\title{
Estimate of Global Solar Radiation by Using Artificial Neural Network in Qena, Upper Egypt
}

\author{
Emad A. Ahmed and M. El-Nouby Adam
}

\begin{abstract}
This paper explores the possibility of developing a prediction model using artificial neural networks (ANNs), which could be used to estimate monthly average daily global solar radiation in Qena, upper Egypt. Results from the paper have shown good agreement between the estimated and measured values of global solar irradiation. A correlation coefficient of 0.998 was obtained with mean bias error (MBE) of $48 \mathrm{Wh} / \mathrm{m} 2$ and root mean square error (RMBE) of $115 \mathrm{Wh} / \mathrm{m} 2$. The comparison between the ANN and empirical model emphasized the superiority of the proposed ANN prediction model. The application of the proposed ANN model can be extended to other locations with similar climate and terrain.
\end{abstract}

Index Terms-Artificial neural network, global solar radiation, sunshine duration.

\section{INTRODUCTION}

Solar energy is the most ancient source of energy; it is the basic element for almost all fossil and renewable types. Solar energy is freely available and could be easily harnessed to reduce our reliance on hydrocarbon-based energy by both, passive and active designs. Precise solar radiation estimation tools are critical in the design of solar systems [1]. Solar radiation data is always a necessary basis for the design of any solar energy conversion device and for a feasibility study of the possible use of solar energy [2]. There is no doubt that the measured data are the best but cannot always be available, in addition to the cost of equipment, maintenance and calibration. Theoretical and empirical models have been postulated to compute the components of the solar radiation [3]-[14]. Some of these models are theoretical, dealing with the solution of the radiative transfer equation, while others are simply regression models. Angstrom (1924) presented the first attempt at estimating global solar radiation was the well-known empirical relation between global solar radiation under clear sky conditions and bright sunshine duration [3].

An artificial neural network (ANN) provides a computationally efficient way of determining an empirical, possibly nonlinear relationship between a number of inputs and one or more outputs. ANN has been applied for modeling, identification, optimization, prediction, forecasting and control of complex systems. ANN models are type of solar prediction models and there have been several articles that have used artificial neural networks for predicting solar radiation [15]-[17].

This paper uses Artificial Neural Network (ANN) method

Manuscript received December 17, 2012; revised January 22, 2013.

The authors are with Physics Department, Faculty of Sciences, South Valley University, Qena, Egypt (e-mail: ealy21@yahoo.com; el_nouby.adam_svu@yahoo.com). to estimate Global solar radiation in Qena based on the number of sunshine hours, day number and location coordinates. Qena $\left(26.17^{0} \mathrm{~N}, 32.7^{0} \mathrm{E}\right)$ is located in the Upper Egypt about $600 \mathrm{Km}$ south of Cairo and its climate is very hot dry in summer and cold in winter. It rarely rains. Also, it receives a large quantity of solar radiation, especially in summer [11].

\section{Methodology}

Daily data of global solar radiation $\left(\mathrm{Wh} / \mathrm{m}^{2}\right)$ and sunshine hours were obtained from South valley university station at Qena, which is one of the stations guides of the Egyptian Meteorological authority.

For predicted global solar radiation the following relation is the generally accepted modified form of the Angstrom-type regression equation, relating the clear sky global solar radiation to sunshine duration [18].

$$
\frac{G}{G_{0}}=a+b \frac{n}{N}
$$

where $G$ is the average daily global radiation, $\mathrm{G}_{\mathrm{o}}$ is average daily extraterrestrial radiation, $\mathrm{n}$ is the day length, $\mathrm{N}$ is the maximum possible sunshine duration, and $\mathrm{a}$ and $\mathrm{b}$ are empirical coefficients. The daily extraterrestrial radiation Go was calculated from the following equation.

$$
\begin{aligned}
G_{o}=\frac{24 * I_{s c}}{\pi}\left[1+0.033 \cos \frac{360 D}{365}\right] \\
{\left[\cos \varphi \cos \delta \sin \omega_{s}+\frac{\pi \omega}{180} \sin \varphi \sin \delta\right] }
\end{aligned}
$$

where $I_{s c}=1367 \mathrm{Wm}^{-2}$ is the solar constant [19], $D$ is the Julian day number, $\varphi$ is the latitude, $\delta$ is the declination angle, $\omega_{\mathrm{s}}$ is the sunset hour. $\delta$ and $\omega$ are given from these formulae [18].

$$
\begin{gathered}
\delta=23.45 \sin \left(360 \frac{284+D}{365}\right) \\
\omega_{s}=\cos ^{-1}[-\tan \varphi \tan \delta]
\end{gathered}
$$

The maximum possible sunshine duration $N$ was calculated using the following equation [18].

$$
N=\frac{2}{15} \omega_{s}
$$

Artificial neural networks have been used widely in many application areas. Most applications use a feed-forward neural network with the back-propagation training algorithm. 
There are numerous variants of the classical back-propagation algorithm and other training algorithms [20]. All these training algorithms assume a fixed ANN architecture and during training, they change the weights to obtain a satisfactory mapping of the data. The main advantage of the feed-forward neural networks is that they do not require a user-specified problem solving algorithm (as is the case with classic programming) but instead they "learn" from examples, much like human beings. Another advantage is that they possess inherent generalization ability. This means that they can identify and respond to patterns which are similar but not identical to the ones with which they have been trained. On the other hand, the development of a feed-forward ANN-model also poses certain problems, the most important being that there is no prior guarantee that the model will perform well for the problem at hand [21].

A feed-forward back-propagation neural network was used in this study. A typical neural network consists of an input, a hidden, and output layer. Other components include a neuron, weight, and a transfer function as shown in Fig. 1.

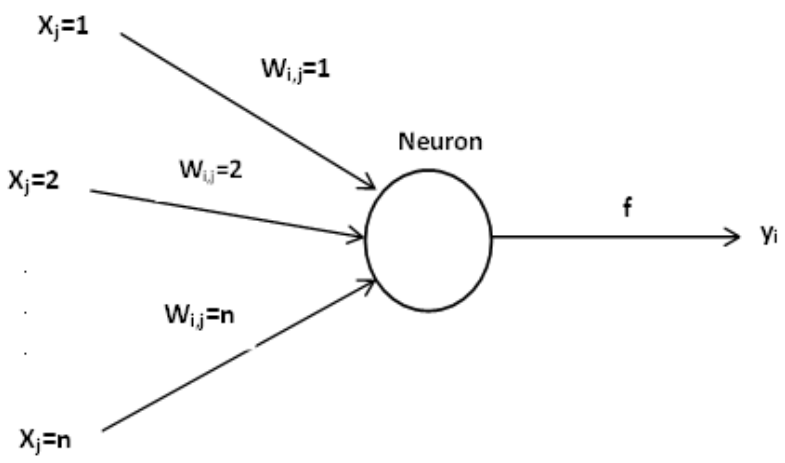

Fig. 1. Typical neuron in a feed forward network.

Estimated values were compared with measured values through correlation and error analysis. The latter was carried out through computation of mean bias error (MBE) and root mean square error (RMSE), represented by the following equations:

$$
\begin{aligned}
M B E & =\frac{\sum_{i=1}^{N}\left(y_{i}-x_{i}\right)}{N} \\
R M B E & =\sqrt{\frac{\sum_{i=1}^{N}\left(y_{i}-x_{i}\right)^{2}}{N}}
\end{aligned}
$$

where $y_{i}$ is an estimated value, $x_{i}$ is a measured value, and $N$ is equal to the number of observations.

\section{RESUlTS AND DISCUSSION}

In this study, ANN and empirical model were applied using the data measured at Qena during 2007.

Fig. 2 shows the monthly mean daily global solar radiation estimated by the above two model in addition to measured data. Clearly, the applied ANN model give estimated values of global solar radiation nearly coinciding with the measured values which better than that estimated by empirical model.

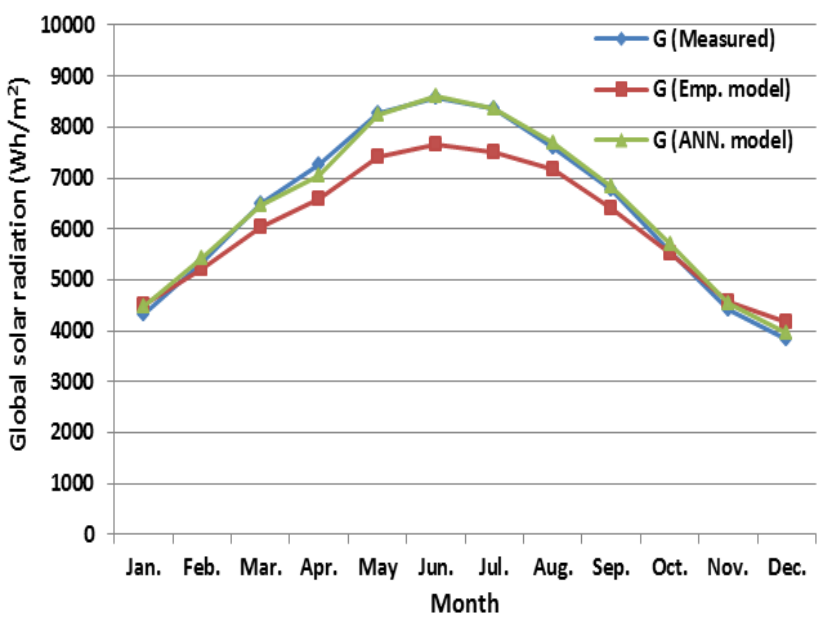

Fig. 2. Monthly mean daily variation of global solar radiation.

The estimates obtained from the empirical model were correlated with the measured values, giving a correlation coefficient $r$ of 0.960 , as shown in Fig. 3. The corresponding MBE was $-335 \mathrm{Wh} / \mathrm{m}^{2}$ and the RMSE was $540 \mathrm{Wh} / \mathrm{m}^{2}$.

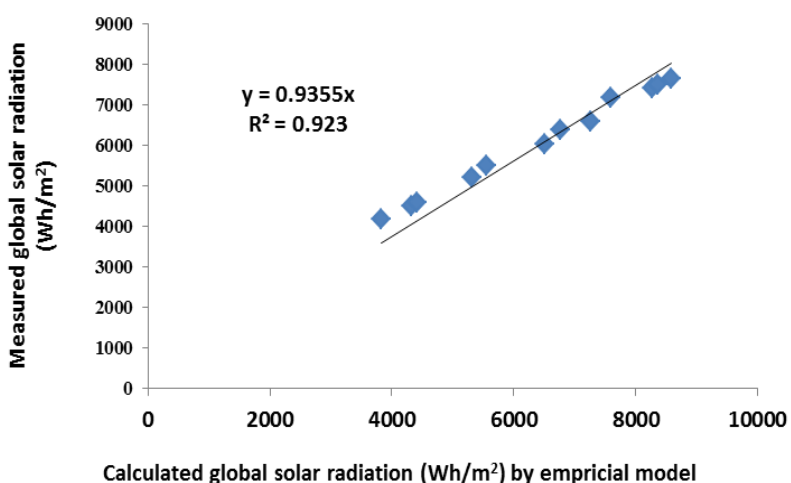

Fig. 3. Comparison between measured and calculated global solar radiation values using empirical model.

The estimates obtained from the ANN model were correlated with the measured values, giving a correlation coefficient $r$ of 0.977 , as shown in Fig. 4. The corresponding MBE was $48 \mathrm{Wh} / \mathrm{m}^{2}$ and the RMSE was $115 \mathrm{Wh} / \mathrm{m}^{2}$.

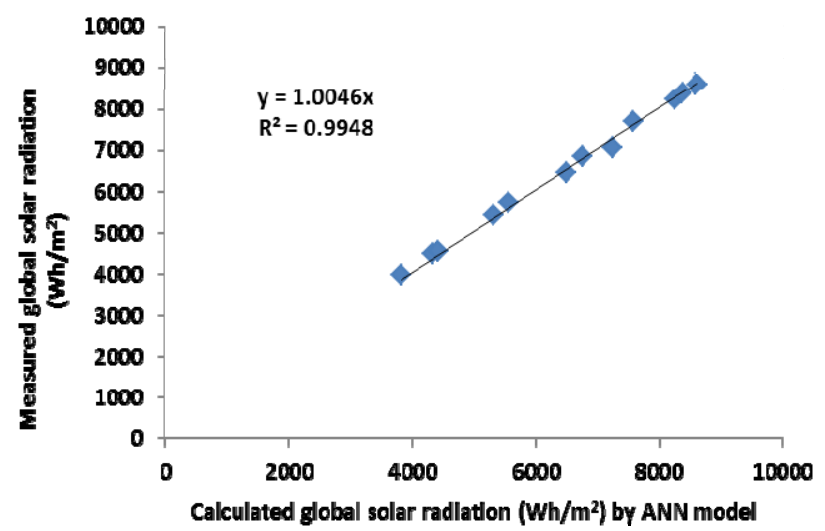

Fig. 4. Comparison between measured and calculated global solar radiation values using ANN model.

These results indicate a good fitting between the estimated and measured monthly average daily global solar irradiation 
values. But the results calculated by ANN model are better than that calculated by empirical model. Table I summarizes the correlations and error analyses which result from the comparison between estimated values (ANN model and empirical) and measured values.

TABLE I. RESULTS OF CORRELATION AND ERROR ANALY

\begin{tabular}{lccc}
\hline \multicolumn{1}{c}{ Model } & $\mathrm{r}$ & $\mathrm{MBE} \mathrm{Wh} / \mathrm{m}^{2}$ & $\mathrm{RMBE} \mathrm{Wh} / \mathrm{m}^{2}$ \\
\hline Empirical model & 0.960 & -335 & 540 \\
\hline ANN model & 0.977 & 48 & 115 \\
\hline \hline
\end{tabular}

\section{CONCLUSIONS}

The use of ANN technique in modeling monthly mean daily solar radiation has been reported. The results of validation and comparative study indicate that the ANN based estimation technique for solar radiation is more suitable to predict the global solar radiation than the empirical regression models. This study confirms the ability of the ANN to predict solar radiation values precisely. Therefore, this ANN model may be suitable for predicting solar radiation at any location provided that samples of the sunshine duration data from the locations are available.

\section{REFERENCES}

[1] M. A. AbdulAzeez, "Artificial neural network estimation of global solar radiation using meteorological parameters in gusau, nigeria," Archives of Applied Science Research, vol. 3, no. 2, pp.586-595, 2011.

[2] K. K. Gopinathau, "Solar sky radiation estimation techniques," Solar Energy, vol. 49, no. 1, pp. 9-11, 1992.

[3] A. Angstrom, "Solar and terrestrial radiation," Roy. Met. Soc., vol. 50, pp. 121-127, 1924

[4] J. A. Prescott, "Evaporation from a Water Surface in Relation to Solar Radiation," Trans. R. Soc. S. Austr., vol. 64, pp. 114-118, 1940.

[5] B. Hourmitz, "Insolation in relation to cloudiness and cloud density," $J$. Met., vol. 2, pp. 154-156, 1945.

[6] M. Daneshyar, "Solar radiation statistics for iran," Solar Energy, vol. 21, pp. 345-349, 1978.

[7] J. Davies, M. Abdel-Wahab, and D. Mekay, "Estimating solar irradiance on horizontal surface," Int. J. Sol. Energy, vol. 2, pp. 405, 1984.

[8] M. Abdel-Wahab, "Simple model for estimation of global solar radiation," Solar and Wind Technology, vol. 2, no. 1, pp. 69-71, 1985.

[9] S. K. Srivastava, O. P. Sinoh, and G. N. Pandy, "Estimation of global solar radiation in uttar pradesh (india) and comparison of some existing correlations," Solar Energy, vol. 51, no. 1, pp. 27-29, 1993.

[10] M. Abdel-Wahab, "New approach to estimate angstrom coefficient," Solar Energy, vol. 51, pp. 241-245, 1993.

[11] S. M. El-Shazly, "Solar radiation component at Qena-Egypt," DOJARAS Quart J. Hungarian Meteorol. Service, vol. 101, pp. 215-231, 1994.
[12] V. Bodescu, "Verification of some very simple clear and cloudy sky models to evaluate global solar irradiance," Solar Energy, vol. 61, no 4, pp. 251-264, 1997.

[13] S. A. Khalil and A. M. Fathy, "An empirical method for estimating global solar radiation over egypt," Acta Polytechnica, vol. 48, no. 5, pp. $48-53,2008$

[14] M. El-Nouby Adam, "Effect of stratospheric ozone in uvb solar radiation reaching the earth's surface at qena, egypt," Atmospheric Pollution Research, vol. 1, pp. 155-160, 2010.

[15] M. A. AbdulAzeez, "Artificial neural network estimation of global solar radiation using meteorological parameters in gusau, nigeria," Archives of Applied Science Research, vol. 3, no 2, pp. 586-595, 2011

[16] J. Mubiru, "Using artificial neural networks to predict direct solar irradiation," Advances in Artificial Neural Systems, pp. 1-6. 2011.

[17] Tamer Khatib, Azah Mohamed, M. Mahmoud, and K. Sopian, "Estimating global solar energy using multilayer perception artificial neural network," International journal of energy, vol. 6, no. 1, 2012.

[18] J. A. Duffie and W.A. Beckman, Solar Engineering of thermal Processes, 2nd Ed. John Wiley, New York, 1994.

[19] C. Frohlich and J. London, Revised instruction manual on radiation instruments and measurements. World climate research program, publication series, no. 7, 1986.

[20] S. Haykin, Neural networks, a comprehensive foundation, New York, MacMillan, 1999.

[21] M. Benghanem, A. Mellit, and S. N. Alamri, "ANN-based modelling and estimation of daily global solar radiation data: A case study," Energy Conversion and Management, vol. 50, pp. 1644-1655, 2009.

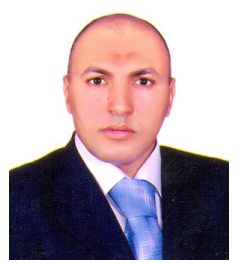

Emad Ali Ahmed was born in Luxor, Egypt, on August 14, 1978. He received his BSc., MSc. and $\mathrm{PhD}$. in physics from South Valley University, faculty of science, Qena, Egypt in 1999, 2005 and 2010, respectively.

$\mathrm{He}$ is currently with physics department, faculty of sciences, South Valley University, Qena, Egypt. His research interests are Atmospheric Physics, Computation of physics, Theoretical \& Applied physics and Application of Computer in Physics.

Now, he worked as Assistant professor and head of Development \& Quality Assurance Unit, deanship of e-learning and distance learning, Jazan University, KSA.

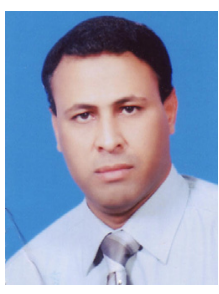

Mahmoud EL-Nouby Adam earned BSc and MSc in physics from Assiut University, faculty of science, Qena, Egypt in 1990 and 1995, respectively and $\mathrm{PhD}$ in Environmental physics from Freiburg University, Germany in 2003.

He is currently with physics department, faculty of sciences, South Valley University, Qena, Egypt. His research interests are Atmospheric Physics, Environmental physics, Air pollution and Solar

radiation \& Energy.

Now, he worked as Assistant professor and head of Development \& Quality Assurance Unit, ALI, King Saud University, KSA. 